\title{
Canadian Thoracic Society CME/CPD Survey
}

Dear CTS Member,

The Canadian Thoracic Society (CTS) prides itself in providing excellence and creativity in its Continuing Medical Education/Continuing Professional Development (CME/CPD) activities. To ensure that we are meeting the needs of our members we wish to confirm, update, and possibly alter some of the $\mathrm{CME} / \mathrm{CPD}$ philosophies, and/or programs that we develop. In that regard, we want to ensure the following:

1. There is a systematic evaluation of the overall CME/CPD aims and goals of the society.

2. There is an evaluation of individual CME/CPD events that are focused on participant satisfaction and provide feedback to speakers, faculty and organizers. There is an emphasis on the degree to which learning objectives are achieved.

3. There is an evaluation of the effectiveness and scope of its educational programs in meeting the overall CME/CPD aims and goals of the society.

4. The society's mission (page 17) statement includes a reference to the CME/CPD aims and goals of the society. The CTS strives to make the CME/CPD aims and goals more specific.

5. That formal policies pertaining to the relationship with corporate sponsors of CME/CPD are maintained.

Your help in measuring our performance will enhance our abilities to provide valuable educational activities in the future.

Over the past five years, the CCTS has developed, sponsored, co-sponsored, and/or accredited the following CME/CPD initiatives:

Clinical Practice Guidelines/Consensus Statements

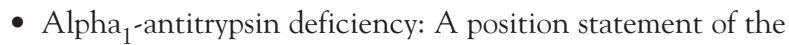
Canadian Thoracic Society. Can Respir J 2001;8:81-8.

- Canadian Thoracic Society recommendations for the management of chronic obstructive pulmonary disease 2003. Can Respir J 2003;10(Suppl A):11A-33A.

- Canadian guidelines for the management of acute exacerbations of chronic bronchitis. Can Respir J 2003;10(Suppl B):3B-32B.

- Adult Asthma Consensus Guidelines Update 2003. Can Respir J 2004;11(Suppl A):9A-18A.

- Canadian Cardiovascular Society and Canadian Thoracic Society position statement on pulmonary arterial hypertension. Can Respir J 2005;12:303-8.

- Canadian Thoracic Society guidelines: Diagnosis and treatment of sleep disordered breathing in adults. Can Respir J 2006;13:387-92.

\section{CTS Annual Scientific Program}

November 2001, Philadelphia, Pennsylvania

November 2002, San Diego, California

October 2003, Orlando, Florida

October 2004, Seattle, Washington

October 2005, Montreal, Quebec

October 2006, Salt Lake City, Utah
Annual Regional Canadian Meetings

Ontario Thoracic Society Conference, Toronto

British Columbia Thoracic Society, Vancouver

CME/CPD Programs

- ATS \& AAAAI Update, May 2003, Toronto, Ontario

- COPD Alliance, November 2004, Montreal, Quebec

- British Columbia Thoracic Society Case Challenges, 2004, Vancouver, British Columbia

- British Columbia Thoracic Society Respiratory Pearls, 2004, Whistler, British Columbia

- Pulmonary Hypertension: translating knowledge into practice, January 2005, Montreal, Quebec

- COPD Alliance, November 2006, Calgary, Alberta

- Sleep Medicine Update, November 2006, Ottawa, Ontario

- Controversies in COPD (2004 and 2006)

- Charting New Courses in Asthma (2006)

We would be grateful if you could complete the short survey below.

Please review the Canadian Thoracic Society's CME/CPD Mission Statement, Aims and Goals, and Guiding Principles (page 17)

Demographics:

I am:

$\square$ a trainee (clinical)

$\square$ a trainee (research or other fellow)

$\square$ finished my formal training

Which of the following best describes you?

$\square$ a) basic scientist

$\square$ b) clinician

$\square$ c) clinician-administrator

$\square$ d) clinician-educator

$\square$ e) clinician-researcher

$\square$ f) clinician-scientist

$\square \mathrm{g})$ allied health care professional

$\square$ h) other

Concerning last year's and/or prior CTS annual meetings, CME/CPD programs, CPG's and Consensus Statements (omit questions that do not pertain to you):

1. Name something that you do differently in your everyday practice or research that has changed because of what you had learned at the CTS meeting.

Write response here 
2. Name something that you do in your everyday practice or research that has NOT changed because of something that you learned at a CTS meeting.

Write response here

3. Do you feel the quality of care you provide in your clinical practice is enhanced as a result of what you have learned at the CTS annual meeting?

$\square$ Yes $\square$ No

4. Do you consider the annual CTS meeting an important source of your annual Royal College Maintenance of Certification points?

$\square$ Yes $\square$ No

5. Do you consider the annual meeting an important mechanism in the maintenance of your professional competence (irrespective of whether you need the points)?

$\square$ Yes $\square$ No

6. If you are primarily a basic science researcher, is the CTS annual meeting of value to you re: your education and/or promotion of your research findings?

$\square$ Yes $\square$ No

7. If you are primarily a clinical researcher, is the CTS annual meeting of value to you re: your education and/or promotion of your research findings?

$\square$ Yes $\square$ No

8. If you are primarily involved in clinical practice is the CTS annual meeting of value to your re: your education and/or promotion of your research findings?

$\square$ Yes $\square$ No

Concerning the format of the annual meeting

9. Does the meeting content strike the right balance between clinical practice and basic science presentations?

$\square$ Too much Basic Science

$\square$ Too much Clinical Practice

$\square$ Balance is appropriate

10. Does the annual meeting effectively showcase important Canadian research (clinical or basic science) in the area of lung disease?

$\square$ Yes $\square$ No

11. Is the area of ethics satisfactorily presented on a regular basis at the annual meeting?

$\square$ Yes $\square$ No

12. The duration of the meeting is:

$\square$ Too long

$\square$ Too short

$\square$ Good as it is

13. The format of the meeting:

$\square$ Should be left as is

$\square$ Should be changed (specify): write response here

14. I have concerns about the present level of involvement from corporate sponsors re: support of CTS's CME/CPD programs.

$\square$ Yes $\square$ No

if "Yes", please explain here
Concerning the CME/CPD mission, aims, and goals of the CTS:

15. I am familiar with the mission statement of the CTS concerning CME/CPD:

$\square$ Yes $\square$ No

16. How familiar are you with the CANMEDS role defined by the Royal College (do not peek ahead!)?

$\square$ Very familiar

$\square$ Somewhat familiar

$\square$ Somewhat unfamiliar

$\square$ Quite unfamiliar

17. It would be important to my personal CME/CPD for the CTS to develop more detailed aims and goals concerning its CME/CPD programs

$\square$ Yes $\square$ No

If you answered yes, please specify:

Write response here

18. Please rank order (from 1 = most important on down, no need to rank all items) the following CANMEDS roles in terms of whether they should be important foci on the CTS's $\mathrm{CME} / \mathrm{CPD}$ programs? (See below for definitions if you are not familiar with these.)

$\square$ Medical Expert
$\square$ Communicator
$\square$ Collaborator
$\square$ Manager
$\square$ Health Advocate
$\square$ Scholar
$\square$ Professional

Definitions of CANMEDS 2005 roles

Medical Expert: MD integrates all CANMEDs roles, applying medical knowledge, clinical skills, and professional attitudes to provision of patient-centred care.

Communicator: MD effectively facilitates MD-patient relationship and dynamic exchanges that occur before, during and after the medical encounter.

Collaborator: MD effectively works within a health care team to achieve optimal patient care.

Manager: MD is integral participant in health care organizations (sustainable practices, resource allocation, effectiveness of system)

Health Advocate: MD uses expertise/influence to advance health and well-being of patients, communities, populations.

Scholar: MD demonstrates life-long commitment to reflective learning, and creation, dissemination, application, and translation of medical knowledge.

Professional: MD is committed to health and well-being of individuals and society through ethical practice, profession-led regulation, and high personal standards of behaviour.

\author{
Thank You \\ Please fax to: \\ Ms. Suzanne Desmarais \\ (1) 613-569-8860
}




\section{Canadian Thoracic Society CME/CPD Mission Statement}

"The CTS will provide Continuing Medical Education/ Continuing Professional Development (CME/CPD) to promote lifelong learning and enhance the competencies and performance of respiratory physicians and other health professionals, trainees, faculty and students in caring for patients with respiratory disease".

\begin{abstract}
AIMS AND GOALS
The CTS will accomplish their 'CME/CPD Mission' through the design and development of educational activities such as CME/CPD programs, research presentations, outcomes evaluation, the promotion of journal reading and e-learning to serve the needs of its members.

1) To provide continuing education in the form of an Annual Meeting. The annual conference is designed to address the educational needs of health care professionals specializing in Respirology and related diseases. The program includes symposia, current research, plenary sessions and pro/con debates. This conference will provide opportunities to network and share current information, as well as to present new and innovative clinical and basic scientific research (including outcomes) with practical applications for contemporary issues. The annual conference offers an educational forum, which addresses:
\end{abstract}

- New findings from basic/clinical research as it relates to respiratory and related disease(s);

- Updates for medical professionals on diagnosis and therapeutics of respiratory diseases;

- Clinical controversies in the management of respiratory disease; and

- Quality assurance/management as related to the structure, process and optimal outcome in the fields of research, diagnosis and patient management.

Specific objectives will be developed for each session and will be presented in the scientific program. Formal evaluations of each session by attendees will be solicited, including an evaluation of the effectiveness of each session and speaker, and of the relevance of the objectives and topics to the professional development needs of the attendee. Suggestions for future topics of interest will be solicited. The planning and development of future meetings will be guided by the results of these evaluations.

2) To provide educational materials for, and to encourage dissemination of research and clinical findings pertinent to Canadian practitioners in respiratory diseases in the form of publications in the Canadian Respiratory Journal, the official journal of the society.

3) To take the initiative in organizing CME/CPD required for the enhancement of education related to respiratory diseases for medical students, residents, fellows and practicing specialists in the field, as well as for other health care providers.

4) To provide guidance to practitioners in the field of respiratory diseases by developing, publishing and disseminating clinical and diagnostic guidelines.

5) To support the Maintenance of Certification Program of the Royal College of Physicians and Surgeons of Canada (RCPSC) and to provide members with information on how to optimize CME/CPD activities according to the model provided by the RCPSC. To provide feedback, in the form of aggregate data, to members on the CME/CPD activity of their subspecialty.

6) To advise Canadian continuing education providers in respiratory diseases on appropriate needs assessments of respirologists on content and evaluation.

7) To survey the membership, from time to time, for their level of satisfaction with $\mathrm{CME} / \mathrm{CPD}$ activities of the society and to solicit opinions on future directions and strategic goals of the CME/CPD programs.

\section{GUIDING PRINCIPLES}

- To provide leadership and advocacy in CME/CPD

- To promote excellence, creativity and innovation

- To promote integrity and high ethical standards

- To promote the philosophy of lifelong learning

- To advocate partnerships

- To avoid bias or discrimination in our CME/CPD

- To strive for continuous improvement in our service delivery

- To seek initiatives that will optimize health

- To provide high quality CME/CPD within our financial and human resources

- To provide ongoing evaluation of our CME/CPD

- To respect CME/CPD guidelines set out by other bodies. 


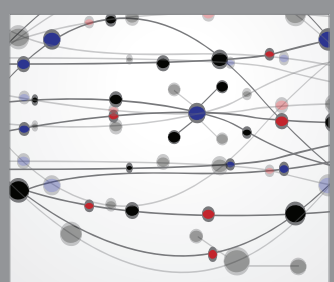

The Scientific World Journal
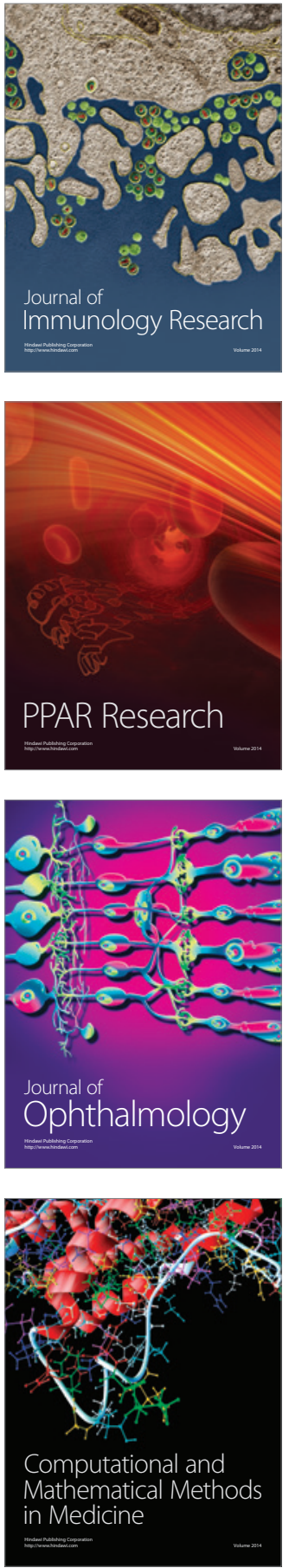

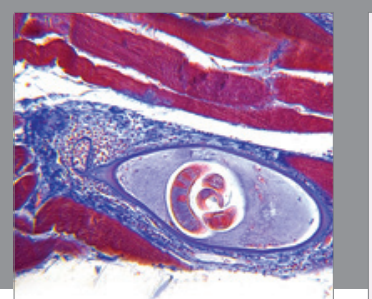

Gastroenterology Research and Practice

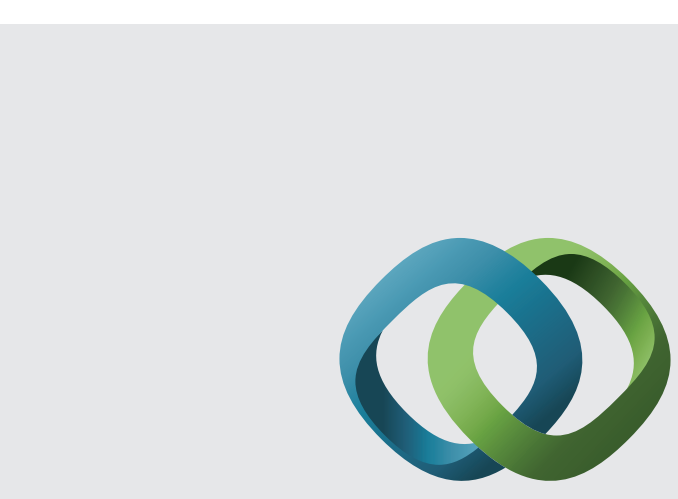

\section{Hindawi}

Submit your manuscripts at

http://www.hindawi.com
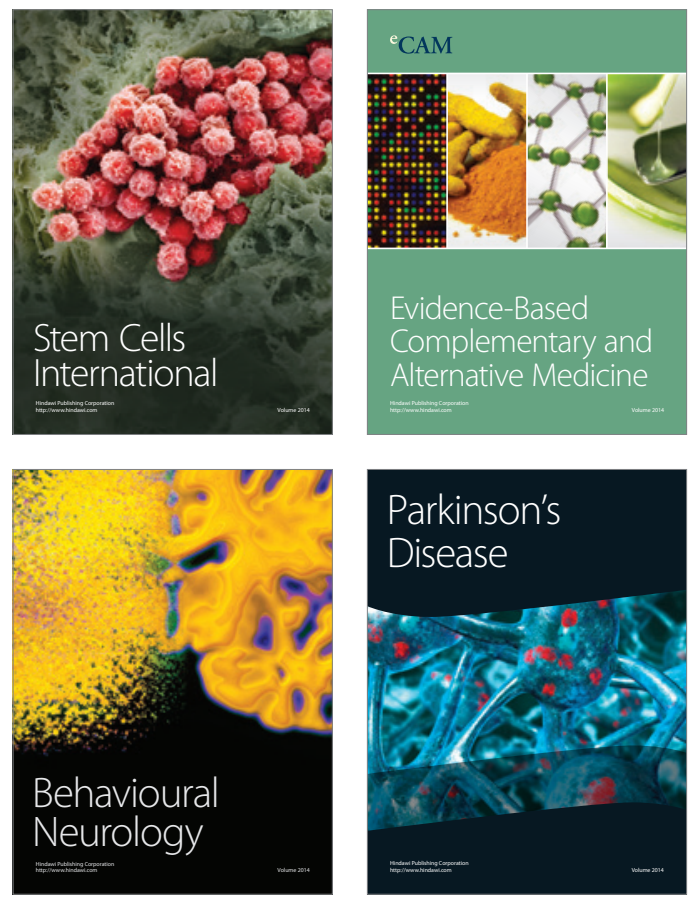
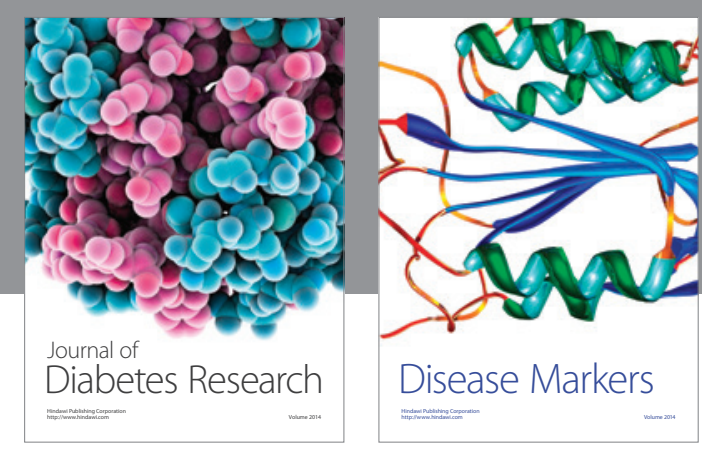

Disease Markers
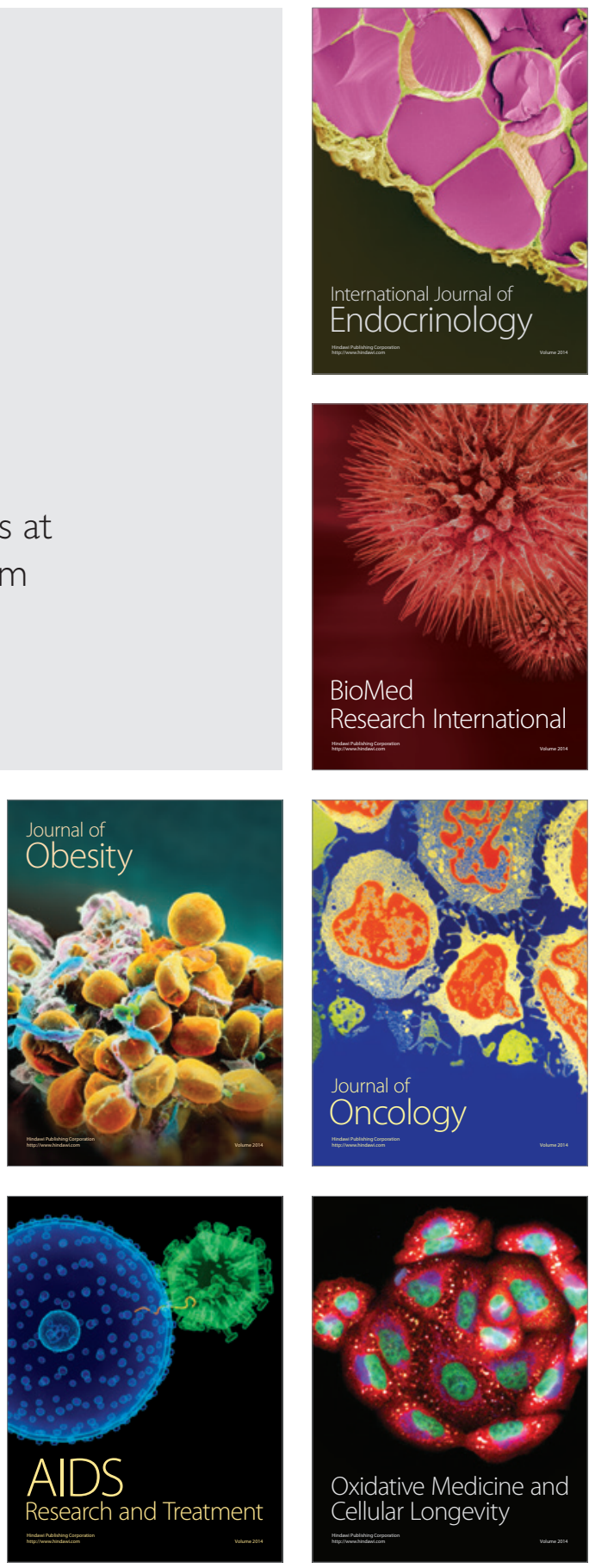